List of Changes in Taxonomic Opinion no. 3

Correspondence Jean Euzéby email address can be found at www.bacterio.net

\section{Notification of changes in taxonomic opinion previously published outside the IJSEM}

The Bacteriological Code deals with the nomenclature of prokaryotes. This may include existing names (the Approved Lists of Bacterial Names) as well as new names and new combinations. In this sense the Code is also dealing indirectly with taxonomic opinions. However, as with most codes of nomenclature there are no mechanisms for formally recording taxonomic opinions that do not involve the creation of new names or new combinations. In particular, it would be desirable for taxonomic opinions resulting from the creation of synonyms or emended descriptions to be made widely available to the public. In 2004, the Editorial Board of the International Journal of Systematic and Evolutionary Microbiology (IJSEM) agreed unanimously that it was desirable to cover such changes in taxonomic opinions (i.e. the creation of synonyms or the emendation of circumscriptions) previously published outside the IJSEM, and to introduce a List of Changes in Taxonomic Opinion [Notification of changes in taxonomic opinion previously published outside the IJSEM; Euzéby et al. (2004). Int J Syst Evol Microbio/ 54, 1429-1430]. Scientists wishing to have changes in taxonomic opinion included in future lists should send one copy of the pertinent reprint or a photocopy or a PDF file thereof to the IJSEM Editorial Office or to the Lists Editor. It must be stressed that the date of proposed taxonomic changes is the date of the original publication not the date of publication of the list. Taxonomic opinions included in the List of Changes in Taxonomic Opinion cannot be considered as validly published nor, in any other way, approved by the International Committee on Systematics of Prokaryotes and its Judicial Commission. The names that are to be used are those that are the 'correct names' (in the sense of Principle 6) in the opinion of the bacteriologist, with a given circumscription, position and rank. A particular name, circumscription, position and rank does not have to be adopted in all circumstances. Consequently, the List of Changes in Taxonomic Opinion must be considered as a service to bacteriology and it has no 'official character', other than providing a centralized point for registering/indexing such changes in a way that makes them easily accessible to the scientific community.

Name/author(s):

Aeromonas culicicola Pidiyar et al. 2002 pro synon. Aeromonas veronii Hickman-Brenner et al. $1988^{*}$ Alcaligenes faecalis Castellani and Chalmers 1919 (Approved Lists 1980) emend. Rehfuss and Urban 2005 Cardiobacterium valvarum Han et al. 2004 emend. Han and Falsen 2005

Phenylobacterium Lingens et al. 1985 emend. Tiago et al. 2005

\begin{tabular}{|cc|} 
Proposed as: & Reference \\
\hline synon. & 2 \\
emend. & 3 \\
emend. & 1 \\
emend. & 4 \\
\hline
\end{tabular}

For reference to Lists of Changes in Taxonomic Opinion nos 1 and 2, see Int J Syst Evol Microbiol 55 (2005) 7, 1403.

${ }^{\star}$ In the paper by Huys et al. (2005), Aeromonas veronii is erroneously cited as Aeromonas veronii Hickman-Brenner et al. 1987.

\section{References}

1. Han, X. Y. \& Falsen, E. (2005). Characterization of oral strains of Cardiobacterium valvarum and emended description of the organism. J Clin Microbiol 43, 2370-2374.

2. Huys, G., Cnockaert, M. \& Swings, J. (2005). Aeromonas culicicola Pidiyar et al. 2002 is a later subjective synonym of Aeromonas veronii Hickman-Brenner et al. 1987. Syst Appl Microbiol 28, 604-609.
3. Rehfuss, M. \& Urban, J. (2005). Alcaligenes faecalis subsp. phenolicus subsp. nov. a phenol-degrading, denitrifying bacterium isolated from a graywater bioprocessor. Syst Appl Microbiol 28, 421-429.

4. Tiago, I., Mendes, V., Pires, C., Morais, P. V. \& Veríssimo, A. (2005). Phenylobacterium falsum sp. nov., an Alphaproteobacterium isolated from a nonsaline alkaline groundwater, and emended description of the genus Phenylobacterium. Syst Appl Microbiol 28, 295-302. 